\title{
Managing dental caries in children: improving acceptability and outcomes through changing priorities and understanding the disease
}

Dr Nicola Innes will be speaking on 'Pathways of care - children with dental caries' on Friday 5 June at the 2009 British Dental Conference and Exhibition, held at the Scottish Exhibition and Conference Centre in Glasgow.

\author{
N. Innes ${ }^{1}$ and D. Evans ${ }^{2}$
}

\begin{abstract}
This new approach to dentistry for children with dental caries provides a deliverable treatment philosophy for practitioners. It centres around leading children into adulthood with a caries-free permanent dentition, with responsibility and ability to care for their mouth and teeth, and without fear of dental treatment. There are three parts: changing attitudes and priorities; redressing the balance of prevention; and taking advantage of new understanding around caries and the biofilm, applying it to less invasive dental treatments which are easier for children to cope with. While dentistry for children should be of as high a standard as for adults, it is not the same as dentistry for adults.
\end{abstract}

The last twenty years have seen spectacular advances in dental science, bringing new materials, aesthetic and restorative techniques, as well as the commonplace use of dental implants. However, the old problems of poor child oral health in the UK remain: extensive dental caries combined with low levels of restorative care. ${ }^{1,2}$ In fact, dental extractions under general anaesthesia seem to be increasingly used to manage the carious primary dentition. ${ }^{3}$ In many ways this is surprising. There are effective, evidencebased techniques for both preventing caries in primary teeth ${ }^{4,5}$ and managing it if it occurs, ${ }^{6}$ interventions which have been part of standard teaching in all UK dental schools for decades. Are the next 20 years simply going to be a continuation of this pattern? If nothing changes, then that seems likely. However, we think that the future need not be so bleak.

There is a new approach to managing the carious primary dentition aimed at delivering effective caries prevention and management strategies which are more acceptable to children (see Figs 1 and 2). The current model of treatment provision has historically developed largely as a result of taking

\footnotetext{
${ }^{*}$ Clinical Lecturer in Paediatric Dentistry, ${ }^{2}$ Senior Lecturer/Honourary Consultant in Paediatric Dentistry, Dundee Dental Hospital and School, University of Dundee, Park Place, Dundee, DD1 4HR ${ }^{*}$ Correspondence to: Dr Nicola Innes Email: N.P.Innes@dundee.ac.uk
}

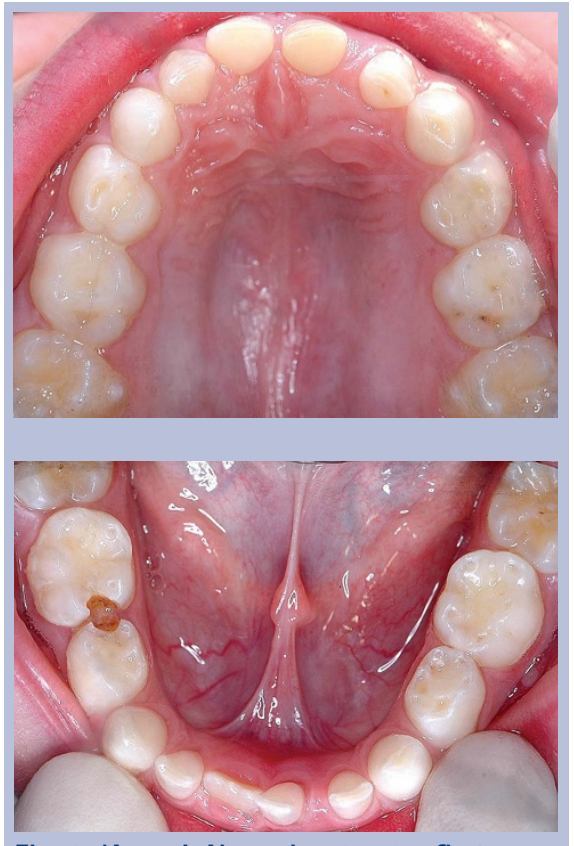

Fig. 1 'Angus': November 2006 - first ever presentation to a dentist with intermittent pain from tooth 85 . Fearful of treatment. Managed using the 'child-friendly' approach

methods for managing the adult dentition and applying them to the primary dentition, without due consideration of the significant differences between them. To date this seems to be neither child- nor dentist-'friendly', hence the problem. This need for a more 'child-friendly' approach has led to development of evidence-led strategies. These are based on the premise that:

the permanent dentition is for life, while

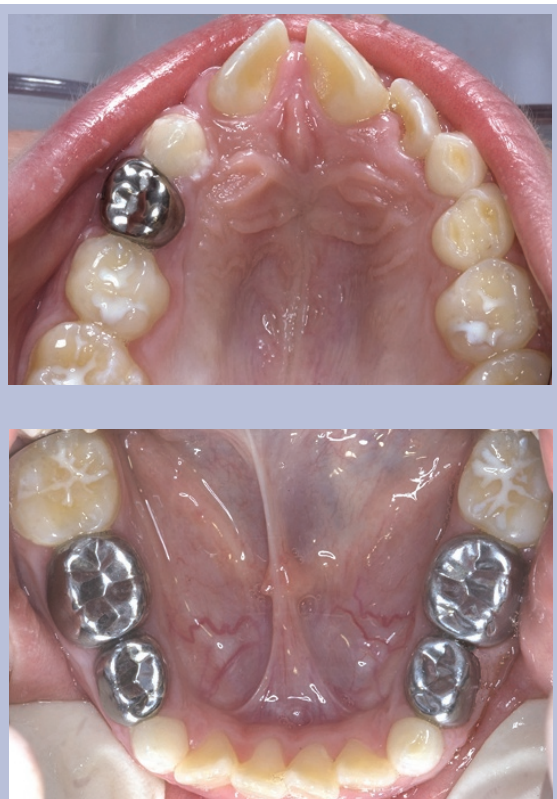

Fig. 2 'Angus': October 2008 - two years after initial presentation. Very happy to have further treatment if necessary but now motivated to work with us towards a cariesfree permanent dentition

the primary dentition is only transient, and runs its course in the mouths of patients who are limited both in their ability to tolerate dental interventions and to give valid consent to those interventions, and who have almost no capacity to accept responsibility for their own oral health.

If a child presents with a carious primary dentition, the standard treatment goals should not be the complete restoration and 
rehabilitation of that dentition, as for an adult, but instead should be:

- To maximise the chances of a cariesfree permanent dentition;

- To minimise the risk of pain/sepsis from carious primary teeth; and

- (Crucially) to minimise the risk of treatment-induced anxiety.

Achieving these goals (all of which are equally important in terms of the whole child) will generally involve progressing through three stages.

\section{STAGE 1: CHANGING ATITUDES AND PRIORITIES}

Dental caries is preventable. Parents/carers must be supported in accepting that their child's oral health is their responsibility, and appreciating that this cannot be completely devolved to the oral health team.

In turn, we need to reconsider our own priorities when looking after the oral health of children. Two possibly controversial examples:

1. Having established that a primary goal is to maintain the permanent dentition free from caries,

radiographic examination of the mixed dentition becomes essential to detect, and manage appropriately, all early, pre-cavitated proximal lesions on first and second molars

2. To avoid treatment-induced anxiety, the temptation to extract a painful tooth on a child's first visit to the surgery needs to be resisted and an alternative, possibly slightly less effective option chosen which would be easier for the child to tolerate. This avoids the child becoming averse to returning for further treatment due to one single extreme experience.

\section{STAGE 2: MAXIMAL PREVENTION}

Most of us will offer preventive programmes to child patients, but might be less comfortable defending those programmes as being 'state of the art'. A strong evidence base supports the key components of a caries preventive plan, ${ }^{4,5}$ including:

- Brushing twice daily with an adult concentration of fluoride toothpaste; spitting out not rinsing after brushing;

- Twice yearly application of fluoride varnish; and

- Fissure sealants.
For prevention it is not a question of 'What should we do?', but 'How can we do it better?' For children who need it, prevention needs to be intense, motivational, involve action planning and be of the highest quality. All this takes chairside time, and perhaps providing these interventions could be supported by the salaried dental services, better use of DCPs or national community-based preventive programmes such as Scotland's Childsmile (www.child-smile.org), which is already showing signs of positive results.

\section{STAGE 3: BIOLOGICAL CARIES MANAGEMENT}

Despite the effectiveness of preventive interventions, children will continue to present with caries in primary teeth. However, clinicians can take advantage of the fact that primary teeth are shed, and that it is often only necessary to slow or arrest the progress of dental caries to meet one of the three main aims of the child-friendly approach: avoidance of pain and sepsis. The carious lesion is driven by the plaque biofilm on the surface of the lesion. Manipulation of the biofilm's environment, making it unfavourable for supporting cariogenic plaque, may be sufficient to slow or arrest the carious lesion until the tooth is shed. This can often be achieved without the use of local anaesthesia, using techniques such as partial caries removal ${ }^{7}$ or sealing in caries with fissure sealants or preformed metal crowns. ${ }^{8}$ There is a growing evidence base supporting these techniques ${ }^{9}$ and for children's preferences for them over more invasive dental techniques based on complete surgical excision of caries followed by a conventional restoration. ${ }^{10-12}$

In practice, carious primary teeth should be assessed on a tooth by tooth basis for risk of pain/sepsis before exfoliation. If judged a 'high risk tooth', a management strategy must be chosen which reduces that risk, without causing treatmentinduced anxiety. It is worth stating two things, however:

1. Active caries must not be simply left, as it will continue

2. Sinuses and abscesses must be looked for and managed by either pulp therapy or extraction, with delay of a few months only acceptable if that period is spent building the child's confidence and co-operation.
If nothing changes in the dentistry we provide for our child patients, the next 20 years will be similar to the last.

New evidence for biological approaches to managing dental caries and effective behaviour change techniques can be taken advantage of. We must also shoulder the responsibility of gently encouraging parents/ carers to accept that their child's oral health is primarily their responsibility. Add in a change of attitude by the dental team to the carious primary dentition, moving from a classic restorative approach to the aim of avoiding pain and sepsis, and it should be possible to help more children reach adulthood with a caries-free permanent dentition, and free from treatment-induced anxiety caused by either inappropriate and over-ambitious attempts to restore primary teeth or a failure to provide high quality treatment.

1. Merrett M C W, Goold S, Jones C M et al. National Dental Inspection Programme of Scotland report of the 2008 survey of P1 children. Scottish Dental Epidemiological Co-ordinating Committee, 2008. http://www.scottishdental.org/index.aspx?o=2153

2. Pitts N B, Boyles J, Nugent Z J, Thomas N, Pine C M. The dental caries experience of 5 -year-old children in Great Britain (2005/6). Surveys coordinated by the British Association for the Study of Community Dentistry. Community Dent Health 2007; 24: 59-63.

3. Moles D R, Ashley P. Hospital admissions for dental care in children: England 1997-2006. Br Dent J 2009; 206: E14.

4. Scottish Intercollegiate Guidelines Network Prevention and management of dental decay in the pre-school child. A national clinical guideline. Edinburgh: SIGN, 2005. SIGN Guideline 83. http:// www.sign.ac.uk/pdf/sign83.pdf

5. Department of Health/British Association for the Study of Community Dentistry. Delivering better oral health. An evidence-based toolkit for prevention. London: Department of Health, 2007.

6. Chadwick B, Dummer P, Dunstan F et al. The longevity of dental restorations. A systematic review. York: NHS Centre for Reviews and Dissemination, University of York, 2001. CRD Report 19

7. Ricketts D N J, Kidd E A M, Innes N, Clarkson J. Complete or ultraconservative removal of decayed tissue in unfilled teeth. Cochrane Database Syst Rev 2006; 3: CD003808. DOI: 10.1002/14651:858. CD003808.pub2.

8. Innes N P, Evans D J, Stirrups D R. The Hal Technique; A randomized controlled clinical trial of a novel method of managing carious primary molars in general dental practice: acceptability of the technique and outcomes at 23 months. BMC Oral Health 2007; 7: 18

9. Thompson V, Craig R G, Curro F A, Green W S, Ship $\mathrm{J}$ A. Treatment of deep carious lesions by complete excavation or partial removal. A critical review. J Am Dent Assoc 2008; 139: 705-712.

10. Rahimtoola S, van Amerongen $E$, Maher $R$, Groen $H$ Pain related to different ways of minimal intervention in the treatment of small caries lesions. ASDC Dent Child 2000; 67: 123-127, 83.

11. Schriks M C, van Amerongen W E. Atraumatic perspectives of ART: psychological and physiological aspects of treatment with and without rotary instruments. Community Dent Oral Epidemiol 2003; 31: 15-20.

12. van Bochove J A, van Amerongen W E. The influence of restorative treatment approaches and the use of local analgesia on children's discomfort. Eur Arch Paediatr Dent 2006; 7: 11-16.

DOI: 10.1038/sj.bdj.2009.471 